\title{
A Multidisciplinary Approach to Treating a Severe Gingival Recession in the Esthetic Zone
}

Machado AW ${ }^{1 *}$, Hodges $\mathbf{R}^{2}$ and Moon $\mathbf{W}^{3}$

${ }^{1}$ Associate Professor, Department of Orthodontics, School of Dentistry, Federal University of Bahia, Brazil

${ }^{2}$ Resident, UCLA Section of Orthodontics, Los Angeles, CA, USA

${ }^{3}$ Program Director, Director of International Orthodontic Programs, UCLA Section of Orthodontics, Los Angeles, CA, USA

\begin{abstract}
Gingival recession is a universal dental problem that can be especially difficult to treat when it involves the esthetic zone. The purpose of this case report is to demonstrate a multidisciplinary approach to treat a severe gingival recession in the esthetic zone for a patient with a high smile line. A rare complication of post removal during endodontic retreatment resulted in a severe gingival recession of the maxillary right central incisor. The gingival asymmetry was highlighted by the patient's high smile line. A multi-disciplinary approach was used to address the gingival recession including a gingival graft, orthodontic extrusion, and esthetic restoration. This case report highlights how a team of dental professionals can work together to treat a severe gingival asymmetry in the esthetic zone, combining periodontics, orthodontics, and prosthodontics.
\end{abstract}

Keywords: Gingival recession; Smile esthetics; Multidisciplinary approach; Orthodontics

\section{Introduction}

Gingival recession (GR) results from the apical migration of gingival tissues and is commonly found in most populations [1]. Reports on prevalence range from 14 to 90 percent, depending on the population being studied [1-3]. The etiology of this problem is multifactorial and associated with root anatomy (dehiscence), tooth position in alveolar bone, orthodontic tooth movement, mechanical trauma, width and thickness of keratinized tissues, and chemical trauma [3]. However, the literature does not associate GR as a potential complication of post removal during endodontic retreatment.

Gingival recession can result in pain from dentin hypersensitivity [4], root caries [5], abrasion [3], fear of tooth loss [6], and unfavorable esthetics [6], especially when it occurs in the esthetic zone. This is especially true in patients with a high lip line that results in excessive gingival display when smiling and speaking. While generalized GR results in the appearance of longer teeth, which is associated with aging, asymmetric gingival margins in the anterior region has been shown to be especially undesirable [3]. When there is a gingival margin discrepancy between the central and lateral incisors, neither laypersons nor dental professionals considered a $2 \mathrm{~mm}$ discrepancy unesthetic [7]. However, when the gingival margin discrepancy was between the central incisors, a discrepancy of only $1.5 \mathrm{~mm}$ was considered unesthetic by laypersons [8]. This confirms that the presence of symmetry between upper central incisors is a paramount goal for esthetic treatment $[9,10]$.

Therefore, treatment of GR can be challenging, especially when it involves the esthetic zone [2]. According to the literature there are several treatment options for GR: periodontal disease control by plaque and calculus debridement [3], flap surgery or guided tissue regeneration (GTR) to cover the root surface $[2,3]$, orthodontic extrusion followed by equilibration or restoration [11], and orthodontically moving the tooth root into the bony housing to correct dehiscence $[2,3]$ or a combination thereof.

The objective of this case report is to describe a multidisciplinary approach to correct a severe case of asymmetric GR in the maxillary central incisors of an adult patient with a high smile line. This case report also highlights GR as a result of a rare complication of post removal during endodontic retreatment.

\section{Case Report}

A 45 year old male initially presented to a prosthodontist with the desire to improve the esthetics of his maxillary incisor crowns (Figure 1A). The upper central incisors had been previously endodontically treated. Initial periapical radiographs reveal failing endodontic treatment with periapical radiolucencies and adequate bone levels in both mesial and distal surfaces (Figure 1B). The patient was referred to an endodontist for retreatment. During post removal, the endodontist reported that the ultrasonic instrument slipped and hit the facial gingiva of the upper right central incisor. This resulted in necrosis of the facial gingiva and apical migration of the gingival margin beyond the mucogingival junction, without interdental bone loss, classified as a Class II Miller GR (Figure 2A) [12]. The endodontist suggested that the patient wait two months as he expected some spontaneous improvement. After this period, no improvement occurred and the

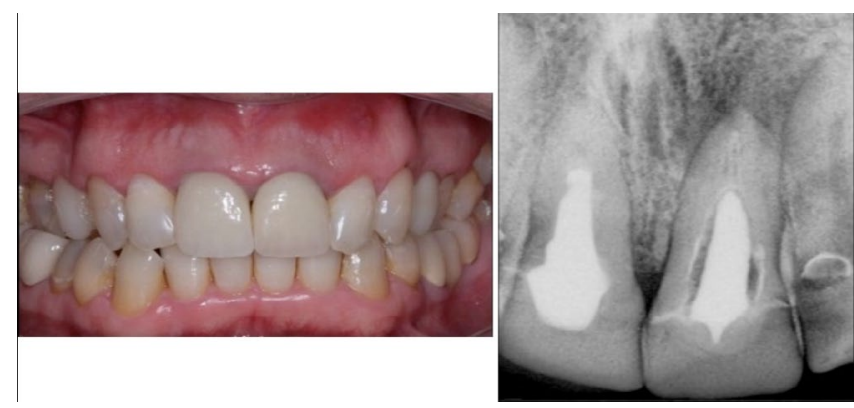

Figure 1: Initial presentation of the patient with a desire to improve esthetics of crowns on central incisors (A). Periapical radiographs of endodontically-treated maxillary central incisors $(\mathrm{B})$

${ }^{*}$ Corresponding author: Andre Wilson Machado, Av. Araújo Pinho, 62, $7^{\circ}$ Andar Canela, Salvador/BA, Brazil, Tel: 55713334 1163; E-mail: awmachado@gmail.com

Received November 21, 2013; Accepted December 10, 2013; Published December 12, 2013

Citation: Machado AW, Hodges R, Moon W (2013) A Multidisciplinary Approach to Treating a Severe Gingival Recession in the Esthetic Zone. Dentistry 3: 175. doi:10.4172/2161-1122.1000175

Copyright: (c) 2013 Machado AW, et al. This is an open-access article distributed under the terms of the Creative Commons Attribution License, which permits unrestricted use, distribution, and reproduction in any medium, provided the original author and source are credited. 

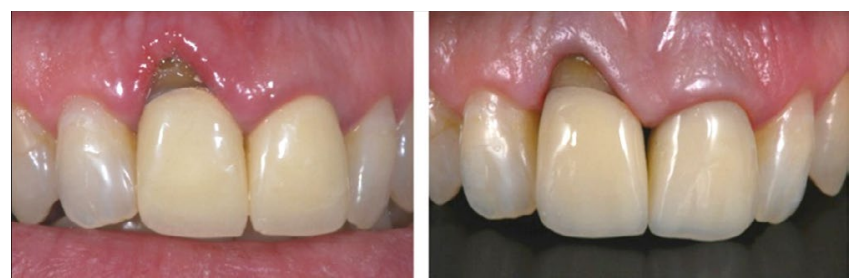

Figure 2: Gingival recession of the upper right central incisor one month after trauma from ultrasonic instrument $(\mathrm{A})$ and after 3 months of healing $(\mathrm{B})$.

\begin{tabular}{|c|c|c|}
\hline \multicolumn{3}{|c|}{ SEQUENCE OF TREATMENT PROCEDURES } \\
\hline Specialties & Type of Treatment & Result \\
\hline Endodontics & Re-treatment & $4.5 \mathrm{~mm}$ gingival recession \\
\hline Periodontics & Gingival graft & $\begin{array}{l}\text { Gingival recession was diminished } \\
\text { but the patient was still left with a } \\
2.5 \mathrm{~mm} \text { gingival margin discrepancy }\end{array}$ \\
\hline Orthodontics & Slow forced extrusion & $\begin{array}{l}\text { Upper centrals gingival margins were } \\
\text { leveled }\end{array}$ \\
\hline Prosthodontics & Porcelain crowns & Favorable esthetic result \\
\hline
\end{tabular}

Table 1: Sequence of treatment procedures.
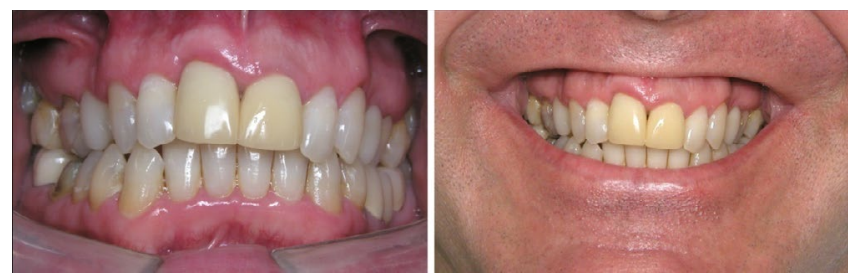

Figure 3: $2.5 \mathrm{~mm}$ relapse of the gingival graft of the upper right central inciso one month after gingival surgery $(A)$, resulting in unfavorable smile esthetics $(B)$.

patient had a $4.5 \mathrm{~mm}$ gingival margin discrepancy between the two central incisors (Figure 2B).

The patient was then referred by the endodontist to the orthodontist and periodontist for a multidisciplinary evaluation. It was decided that a combined approach was going to be preferred starting with a periodontal graft followed by a possible orthodontic extrusion (Table 1).

The soft tissue graft surgery utilized a laterally positioned flap with an oblique incision into the mucosa and elevation of a full thickness flap to the mucogingival junction. A split thickness flap was prepared in the area apical to the mucogingival junction. A connective tissue graft was harvested from the palate and sutured over the root, which had been treated with an enamel matrix protein preparation (Emdogain). The flap was positioned as to cover the connective tissue graft and sutured.

Although the result was favorable and the GR was diminished, two months after the gingival graft the patient was still left with a $2.5 \mathrm{~mm}$ gingival margin discrepancy, which resulted in a deleterious impact on the smile esthetics (Figure 3). At this stage the patient had two provisional crowns placed and then orthodontic brackets were bonded on all maxillary teeth except the second molars. A rigid rectangular stainless steel arch wire was placed in all brackets to stabilize the dentition except for the upper right central incisor. For this tooth, the bracket was placed gingivally and a very light nickel-titanium (.012 $\mathrm{NiTi}$ ) was inserted in the bracket (Figure 4A). The incisal edge of the upper right central was recontoured prior to extrusion to eliminate interference with lower incisors. The tooth was slowly extruded for 5 months until the gingival margins of the upper centrals were leveled (Figure $4 \mathrm{~B}$ and C). The same appliances were left in place for 4 months to stabilize the extrusion prior to debonding.

After removal of orthodontic appliances, the patient had dental whitening and the upper laterals incisal edges were recontoured to improve teeth optimal esthetic anatomy (Figure 5). After those procedures, patient was referred to the prosthodontist for placement of porcelain crowns. The final result was highly esthetic even though a $0.5 \mathrm{~mm}$ relapse occurred with the migration of the gingival margin (Figure 6).

\section{Discussion}

Although GR's etiology is multi-factorial [2,3], this case is unique in that the gingival defect was due to an accident during the manipulation of an ultrasonic instrument for post removal. Although the endodontist reported that the cause of the recession was generated because the ultrasonic instrument hit the gingiva, scientific evidence does not support the idea that the trauma alone could cause the GR. The literature cites numerous potential complications of post removal with an ultrasonic instrument, including dentinal cracking and excessive heat generation $[13,14]$.

This patient experienced severe apical migration of the facial gingival margin, but the interdental bone height was maintained which made this gingival recession less severe to treat [12]. This patient also
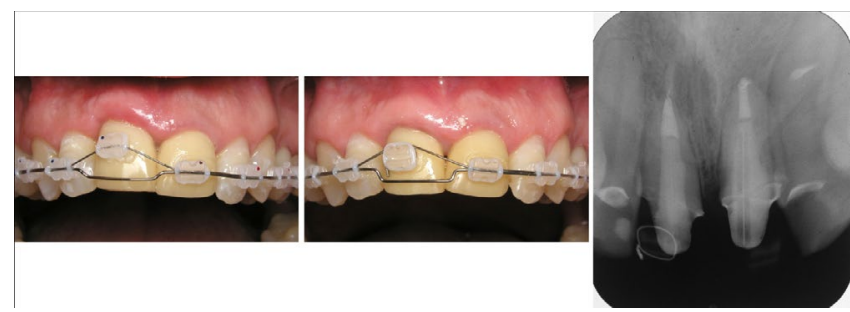

Figure 4: (A) Orthodontic appliances used to slowly extrude the upper right central incisor. (B) The gingival margins of the central incisors were level after 5 months of extrusion. (C) Periapical radiographs of the central incisors after 5 months of extrusion.
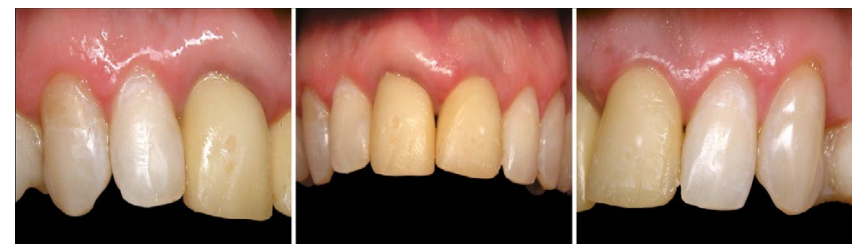

Figure 5: The incisal edges of the upper lateral incisors were recontoured and the patient underwent dental whitening after removal of orthodontic appliances.
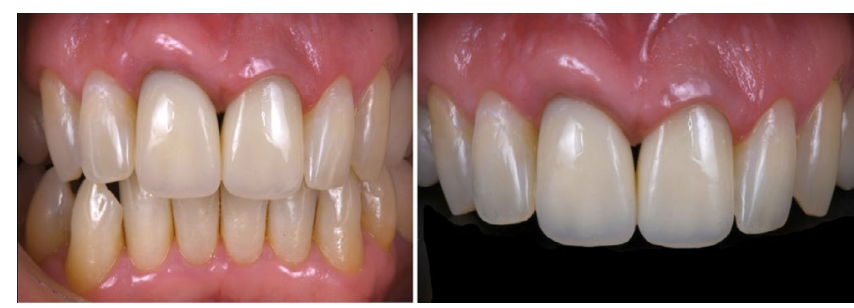

Figure 6: The final result after placement of porcelain crowns on the upper central incisors. 
had a high smile line, which highlights the gingival asymmetry. The combination of the severe gingival asymmetry and high smile line made this case especially difficult to treat and required a multi-disciplinary approach.

There were three different options to consider for treatment of this gingival asymmetry: gingival surgery, orthodontic intrusion followed by cosmetic dentistry, or orthodontic extrusion followed by cosmetic dentistry. The decision of which treatment is best is based on many factors: (a) Central incisor shape and proportion [15-17]; (b) Smile arc $[15,16]$; (c) Amount of gingival display when smiling [11,15]; (d) Crown-root ratio [16]; and (e) Gingival sulcus depth of central incisors $[11,15]$.

In this case, the upper left central had an ideal width/length ratio and the damaged upper right central appeared too long. This information indicated that treatment should result in shortening the crown length of this tooth, matching to the left central width/length proportion. This outcome could be accomplished by a gingival graft, guided tissue regeneration, or orthodontic extrusion followed by incisal edge equilibration or tooth restoration.

When the vertical position of the upper incisors may be changed by extrusion or intrusion, it is important to evaluate the smile arc. When deciding whether to alter a clinical crown by gingival surgery or orthodontic tooth movement, it is important to assess whether the incisal edges are ideally placed in the smile arc. In this case, both central incisors were properly placed in the smile arc, so correction with gingival surgery could be considered as the treatment option. Orthodontic extrusion may also be considered if the incisal edge position is maintained by placing a final restoration after extrusion.

The amount of gingival display, when smiling, plays a critical role in determining how to address a gingival margin discrepancy in the anterior region. In fact, the amount of gingival display when smiling contributes to the decision as to whether to treat a gingival asymmetry or not. This patient presented with a high lip line and excessive gingival display when smiling, so the gingival asymmetry needed to be addressed. Thus, it was determined that a gingival graft in conjunction with orthodontic extrusion of the upper right central would provide a more esthetic result by matching the ideally sized upper left central incisor. Ultimately, the primary objective was to achieve symmetry between upper centrals that is vital in smile esthetics [17].

When considering forced orthodontic extrusion, the root size and shape need to be considered. If the root is short, excessive extrusion could result in a crown-root ratio less than 1:1 after the final restorations are placed, resulting in instability due to insufficient bone around the root [16]. In this case, the crown-root ratio prior to treatment was 1:1.6.

When the gingival discrepancy is severe, as in this case, gingival surgery in conjunction with orthodontics and cosmetic dentistry should be considered. During forced orthodontic extrusion, it has been shown that the tooth will carry the bone and gingiva [16]. Slow, gentle extrusion with light continuous force provides a greater probability that bone and gingival attachment will follow the tooth. Conversely, if heavy forces are used, then the bone may not follow the tooth, and the clinical crown will increase [16]. In this case, a heavy continuous wire was used to anchor the dentition and to prevent compensatory intrusion while forced eruption was being performed with a light nickel titanium wire on the upper right central incisor. This provided a light, continuous force and allowed the alveolar bone and gingival attachment combined with the gingival graft to follow the extrusion of the tooth.
When gingival surgery and orthodontics with cosmetic dentistry are both planned to correct a gingival asymmetry, it is important to consider the timing of the gingival graft. Kokich [11] reports that it is important to do the gingival graft prior to removing orthodontic appliances to allow for fine-tuning of the gingival margins. In this case a gingival graft was performed prior to orthodontic extrusion. This order was imperative in this case to decrease the amount of extrusion needed to correct the gingival discrepancy. Without the gingival graft, it would not have been possible to extrude the tooth sufficiently without compromising the crown-root ratio of the tooth.

The gingival graft that was performed in this case relapsed approximately $2.5 \mathrm{~mm}$ after healing. According to the literature the factors associated with a graft failure include: smoking [18], lack of adequate blood supply, inflammation, and clinical skill [19]. There is no clinical evidence to suggest that the gingival graft failure in this case resulted from any of these causes. The relapse was most likely due to the extent of the gingival defect that was corrected.

Re-intrusion following forced orthodontic extrusion is a common problem if proper retention is not obtained [16]. After forced orthodontic extrusion, the principal fibers of the periodontium become stretched and oriented obliquely, increasing the likelihood of re-intrusion of the tooth. Therefore, retention after extrusion is vitally important to prevent relapse, and it has been reported that it requires 6 months for the principal fibers to reorganize and stabilize the extruded position of the tooth [16]. In this case, the patient demanded appliance removal after only 4 months of retention. It is hypothesized that since this period was not sufficient to allow time for the principal fibers to reorganize, the tooth did intrude approximately $0.5 \mathrm{~mm}$ after the final restoration was placed.

This case demonstrates the value of having effective communication between dental specialties and the necessity to work together to achieve the optimal esthetic result. The timing and order of treatment was critical and needed to be planned in advance, prior to any one specialty beginning treatment. This required constant communication between the providers in order to increase the likelihood of achieving a more effective and efficient result from a multidisciplinary approach.

\section{Conclusion}

Extreme care should be taken when using an ultrasonic instrument for post removal during an endodontic re-treatment because although it's very rare it could result in a severe gingival recession. This case report also highlights how a team of dental professionals can work together to treat a severe gingival asymmetry in the esthetic zone, combining periodontics, orthodontics, and prosthodontics.

\section{References}

1. Slutzkey S, Levin L (2008) Gingival recession in young adults: occurrence, severity, and relationship to past orthodontic treatment and oral piercing. Am J Orthod Dentofacial Orthop 134: 652-656.

2. Kassab MM, Cohen RE (2003) The etiology and prevalence of gingival recession. J Am Dent Assoc 134: 220-225.

3. Tugnait A, Clerehugh V (2001) Gingival recession-its significance and management. J Dent 29: 381-394.

4. Al-Wahadni A, Linden GJ (2002) Dentine hypersensitivity in Jordanian dental attenders. A case control study. J Clin Periodontol 29: 688-693.

5. Lawrence HP, Hunt RJ, Beck JD (1995) Three-year root caries incidence and risk modeling in older adults in North Carolina. J Public Health Dent 55: 69-78.

6. Smith RG (1997) Gingival recession. Reappraisal of an enigmatic condition and a new index for monitoring. J Clin Periodontol 24: 201-205. 
Citation: Machado AW, Hodges R, Moon W (2013) A Multidisciplinary Approach to Treating a Severe Gingival Recession in the Esthetic Zone. Dentistry 3: 175. doi:10.4172/2161-1122.1000175

7. Kokich VO Jr, Kiyak HA, Shapiro PA (1999) Comparing the perception of dentists and lay people to altered dental esthetics. J Esthet Dent 11: 311-324.

8. Kokich VO, Kokich VG, Kiyak HA (2006) Perceptions of dental professionals and laypersons to altered dental esthetics: asymmetric and symmetric situations. Am J Orthod Dentofacial Orthop 130: 141-151.

9. Lombardi RE (1973) The principles of visual perception and their clinical application to denture esthetics. J Prosthet Dent 29: 358-382.

10. Rufenacht C (1990) Fundamentals of Esthetics. Quintessence Pub Co.

11. Kokich V (1993) Esthetics and anterior tooth position: an orthodontic perspective. Part II: Vertical position. J Esthet Dent 5: 174-178.

12. Miller PD Jr (1985) A classification of marginal tissue recession. Int J Periodontics Restorative Dent 5: 8-13.

13. Budd JC, Gekelman D, White JM (2005) Temperature rise of the post and on the root surface during ultrasonic post removal. Int Endod J 38: 705-711.
14. Huttula AS, Tordik PA, Imamura G, Eichmiller FC, McClanahan SB (2006) The effect of ultrasonic post instrumentation on root surface temperature. J Endod 32: 1085-1087.

15. Spear FM, Kokich VG (2007) A multidisciplinary approach to esthetic dentistry Dent Clin North Am 51: 487-505.

16. Kokich VG (2006) Adjunctive role of orthodontic therapy. (10thedn), Saunders - Elsevier, St. Louis, Missouri.

17. Machado AW, Moon W, Gandini LG (2013) Influence of maxillary incisor edge asymmetries on the perception of smile esthetics among orthodontists and laypersons. Am J Orthod Dentofacial Orthop 143: 658-664.

18. Ah MK, Johnson GK, Kaldahl WB, Patil KD, Kalkwarf KL (1994) The effect of smoking on the response to periodontal therapy. J Clin Periodontol 21: 91-97.

19. Langer $B$, Langer $L$ (1985) Subepithelial connective tissue graft technique for root coverage. J Periodontol 56: 715-720. 